\title{
X-linked anhidrotic ectodermal dysplasia (ED1) in men, mice, and cattle
}

\author{
Cord DröGEMÜLleR*, Ottmar DistL, \\ Tosso LeEB \\ Institute of Animal Breeding and Genetics, School of Veterinary Medicine Hannover, \\ Bünteweg 17p, 30559 Hannover, Germany
}

(Accepted 4 February 2003)

\begin{abstract}
Ectodermal dysplasias are a large group of rare genetic disorders characterized by impaired development of hair, teeth, and eccrine glands in humans, mice, and cattle. Here, we review the cloning, mutation analyses, and functional studies of the known causative genes for the X-chromosomal anhidrotic ectodermal dysplasia (ED1) in these species. Mutations in the ectodysplasin 1 (EDI) gene are responsible for X-linked anhidrotic ectodermal dysplasia. The ED1 gene encodes a signaling molecule of the tumor necrosis factor family that is involved in development of ectodermal appendages. The bovine disorder may serve as an animal model for human ED1.
\end{abstract}

ED1 / ectodysplasin / comparative bovine genome mapping / hypotrichosis / anodontia

\section{ANHIDROTIC ECTODERMAL DYSPLASIA IN MEN AND MICE}

\subsection{Phenotype}

Clinical geneticists have recorded over 100 evidently distinct human syndromes named ectodermal dysplasia (ED) that affect the development of sweat glands, hair, teeth and nails, together or in different combinations [22]. The embryonic development of all these structures is the result of interactions between the epithelium and mesenchyme. The most common form of ED in man, the anhidrotic (hypohidrotic) ectodermal dysplasia (ED1, also called EDA, HED or Christ-Siemens-Touraine syndrome) is characterized by heat intolerance with excessively dry skin due to the absence of sweat glands, and abnormal spiky or absent teeth. Affected individuals have sparse hair on the scalp and body, whereas facial and pubic hair are unaffected. Recently, the genes for the X-linked ED1 (MIM305100 [14,22]) and two indistinguishable, autosomally inherited types of ED (MIM604095; MIM606603 [12,13,22]) were cloned.

\footnotetext{
* Correspondence and reprints

E-mail: cord.droegemueller@tiho-hannover.de
} 


\subsection{Genetics}

Mutations in the X-linked EDl gene have been shown to be causative for human X-linked ED1 [14,25] as well as for the similar phenotype of the tabby (ta) mouse mutant $[11,27]$. Structural analysis of the human ectodysplasin 1 and murine tabby protein revealed that $\mathrm{ED} 1 / \mathrm{Ta}$ is a member of the tumor necrosis factor (TNF) family $[10,18]$. The transcription of the EDl gene has been found to undergo complicated alternative splicing yielding different ectodysplasin 1 isoforms [1], but only the two longest splice variants, the 391-residue A1 isoform and the 389-residue A2 isoform, encode proteins with a partially defined physiological function. ED1-A1 and ED1-A2 represent transmembrane proteins with an intracellular N-terminus. The extracellular part of these two isoforms contains a collagen-like Gly-X-Y repeat that mediates trimerization and the TNF-like signaling domain at the C-terminus. The two isoforms differ by the presence or absence of the two amino acids ${ }^{307} \mathrm{~V}$ and ${ }^{308} \mathrm{E}$ located in the TNF domain. ED1-A1 and ED1-A2 bind to their specific receptors in a distinct class of epithelial cells [30]. The A1 isoform binds specifically to a receptor called downless (DL) or EDA receptor (EDAR) while ED1-A2 binds to a different receptor termed the X-linked EDA receptor (XEDAR). Before ectodysplasin 1 isoforms can bind to their receptors, they need to be cleaved and released from the cell surface as soluble homotrimeric ligands by furin proteases $[3,9]$. Until now no report describing a mutation of $X E D A R$ in any mammalian species has been published, and the function of the ED1-A2 isoform and its receptor XEDAR remain elusive. The degree to which any particular ED1 isoform is sufficient for the formation of hair, sweat glands or teeth remained unclear until it was shown that the transgenic expression of the mouse ED1-A1 isoform in tabby males rescued the development of several skin appendages [28]. The importance of the ED1-A1 isoform is highlighted by the fact that mutations in its receptor DL/EDAR are responsible for the ED phenotype of downless mice as well as some rare cases of human autosomal dominant and recessive inherited ED [12,20].

The superfamilies of TNF ligands and TNFR receptors have been known as key regulators of apotosis and cell death [17], but the role in the formation of hair follicles and eccrine glands became apparent when ED1 and EDAR were discovered. Members of the TNFR family that contain an intracellular death domain initiate signaling by recruiting cytoplasmic death domain adapter proteins [17]. The signaling routes downstream of DL/EDAR are mediated by the kinase-dependent activation of the nuclear factor (NF) $\kappa \mathrm{B}$ in a dose dependent manner and these activities are impaired in tabby and downless mice [15, 16]. Through the cloning of the murine crinkled gene, the next element of the ED1-DL/EDAR signal transduction chain was discovered. The crinkled mouse mutant has a hypohidrotic ectodermal dysplasia phenotype identical to that of the downless and tabby mutants. The crinkled gene product represents an 
adaptor protein that was subsequently termed EDAR associated death domain protein (EDARADD) $[13,31]$. A missense mutation in the orthologous HSA 1q42-q43 EDARADD gene was reported in a family segregating for autosomal ED [13]. During hair follicle morphogenesis and in the epidermis, EDAR is activated by ED1-A1 and uses EDARADD as an adaptor to form an intracellular signal-transducing complex that leads to $\mathrm{NF} \kappa \mathrm{B}$ activation [13]. A possible function of $\mathrm{NF} \kappa \mathrm{B}$ is to regulate the cellular decision between proliferation and differentiation. A recent study showed that mice with suppressed $\mathrm{NF} \kappa \mathrm{B}$ revealed defective early morphogenesis of hair follicles, exocrine glands and teeth, identical to tabby and downless mutant mice [24].

\section{ANHIDROTIC ECTODERMAL DYSPLASIA IN CATTLE}

\subsection{Phenotype}

Hereditary and congenital ectodermal dysplasias in cattle are reported in a variety of clinical reports [26]. Under this heading, a broad spectrum of inherited ectodermal abnormalities are summarized ranging from alterations of certain appendages of the skin to the absence of hair in variable areas of the integument [21]. A rare bovine X-linked ectodermal dysplasia phenotype (MIA000543 [21]) shows striking similarities to the human X-linked ED1 phenotype. This congenital X-linked hypotrichosis with missing teeth in cattle appears in clinically slightly variable forms with graded severity of tooth and hair defects in different breeds [2,4,23,29]. Other reported forms of hypotrichosis in cattle are phenotypically less similar to these cases. Recently, two independent cattle pedigrees showed congenital hypotrichosis with oligodontia [6,8]. The affected bulls of a black-and-white German Holstein cattle pedigree showed a generalized hypotrichosis, an almost complete lack of teeth, and the complete absence of eccrine nasolabial glands (Fig. 1D) [6]. A further case of a similar phenotype characterized by hypotrichosis and nearly completely missing teeth has been observed in a family of red-andwhite German Holstein cattle (Fig. 1C) [8]. The histological examination of the skin showed a very thin dermis with sparse, atrophic hair follicles and a reduced density of sweat glands. Furthermore, a complete absence of eccrine nasolabial, tracheal and bronchial glands was observed [8]. For the affected male animals in both families a common ancestor could only be found on the maternal path indicating an $\mathrm{X}$-chromosomal monogenic recessive inheritance of the disorder (Figs. 1A, 1B). These new cases prompted a molecular genetic investigation of this congenital disorder in cattle.

\subsection{Cloning of the bovine $E D 1$ gene}

The X-chromosomal EDl gene was selected as a candidate gene for this bovine disorder. Using the comparative mapping approach to isolate the bovine 

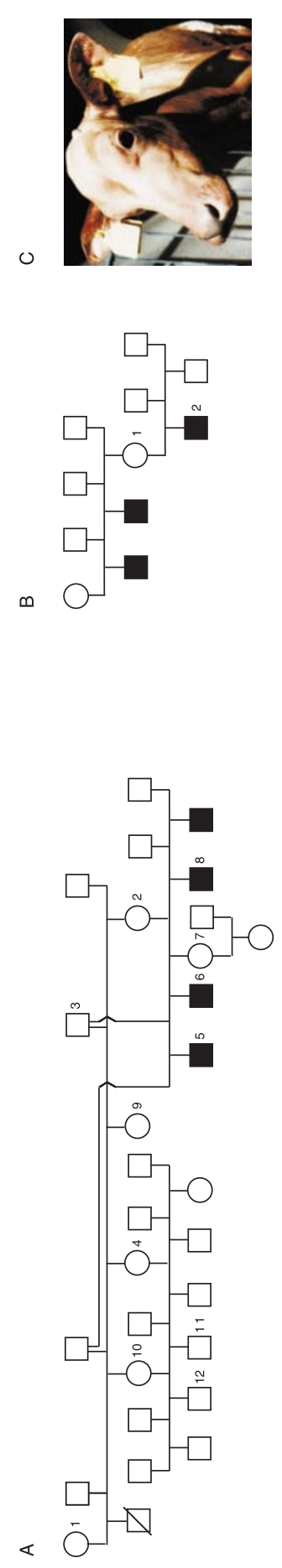
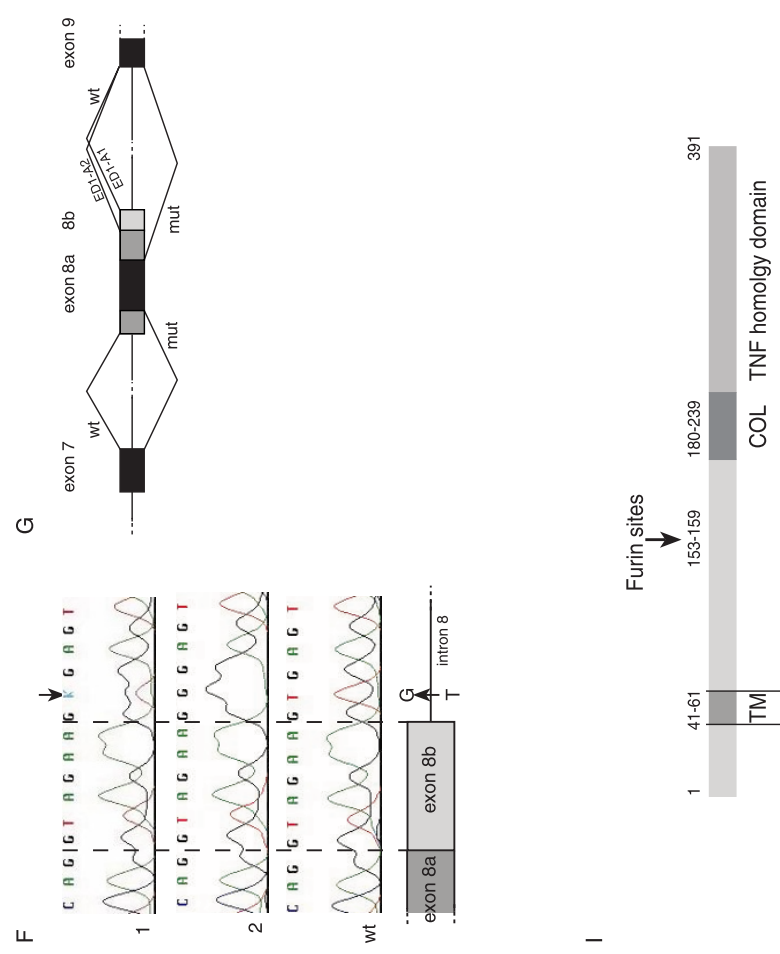

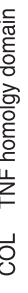
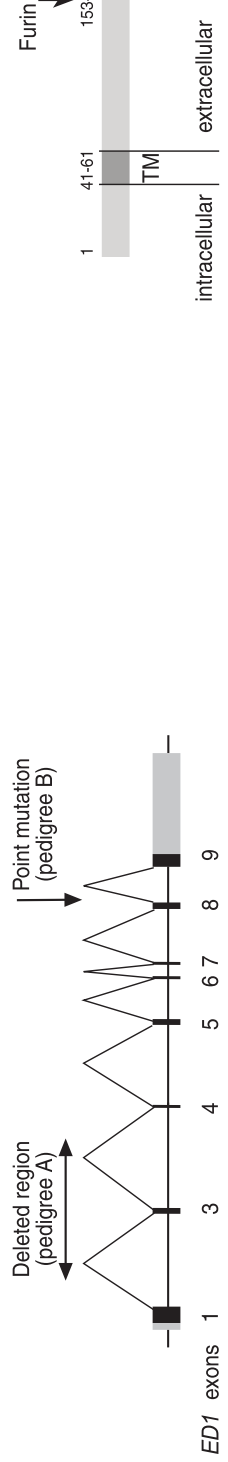

I 
Figure 1. Experimental findings in X-linked anhidrotic ectodermal dysplasia (ED1) in cattle. (A) Pedigree of the black-and-white German Holstein cattle family. Samples from the numbered animals were available for the molecular genetic analyses. (B) Pedigree of the red-and-white German Holstein family. Samples from the numbered animals were available for the molecular genetic analyses. Phenotypic data from the other affected animals were obtained from the farmer's records. (C) Red-and-white German Holstein calf affected with anhidrotic ectodermal dysplasia. Generalised hypotrichosis is clearly visible. (D) Black-and-white German Holstein calf affected with anhidrotic ectodermal dysplasia. Moderate hypotrichosis can be seen. (E) Mutation analysis of genomic DNA of the animals of pedigree I. EDI exons were PCR amplified from animals 1-12 (Fig. 1A). PCR primers flanking exon 3 did not generate the $409 \mathrm{bp}$ PCR product on the DNA of affected animals 5, 6 and 8 indicating a deletion of this genomic region (M: 100 bp-ladder; wt: wild-type cattle DNA). (F) Sequence analysis of genomic DNA of the animals 1 and 2 of pedigree II (Fig. 1B). PCR products from exon 8 together with flanking regions were obtained from each animal and directly sequenced. An arrow denotes the position of the point mutation. Note that the affected animal (No. 2) is hemizygous for the IVS $8+2 \mathrm{~T}>\mathrm{G}$ mutation while its mother (No. 1) is a heterozygous carrier of this mutation (wt: wild-type cattle DNA). (G) Consequences of the EDl gene splice site point mutation. Splicing patterns in wildtype (wt) and affected (mut) animals. Normal splicing results in the production of ED1-A1 and ED1-A2, which differ by the presence or absence of six nucleotides encoded by exon 8b. The two transcripts ED1-A1 and ED1-A2 are schematically indicated in the upper part. RT-PCR sequencing revealed that in the affected calf with the IVS $8+2 \mathrm{~T}>\mathrm{G}$ mutation, not only splicing at the $5^{\prime}$ splice site following exon $8 \mathrm{~b}$ is disrupted, but also the splicing at the $5^{\prime}$ splice site following exon $8 \mathrm{a}$. Even more surprising, the splicing at the $3^{\prime}$ splice site before exon 8 is also altered and a cryptic $3^{\prime}$ splice site within the normal exon 8 is used to give a single type of aberrant transcripts (lower part). (H) Genomic organization and splicing pattern of the bovine EDl gene. The mutations in the examined pedigrees are indicated by the arrows. (I) A schematic representation of ectodysplasin-A1 protein (modified from [19]). TM, transmembrane domain; COL, collagen-like (Gly-X-Y) repeats; TNF, tumor necrosis factor homology subdomain. The affected animals from pedigree A express a truncated ED1 protein lacking amino acids 133-391. In the affected calf from pedigree B amino acids 265-267 and 295-308 are missing from the mutant ED1 protein.

ED1 gene, cattle BAC libraries were screened with a heterologous cDNA probe from the human EDI gene and additional heterologous PCR-amplified probes. This resulted in the construction of a 480-kb BAC contig mapped on BTA Xq22-Xq24 [5]. Partial sequence analysis of this contig revealed the presence of eight $E D 1$ exons with the entire open reading frame of the ED1-A1 and ED1-A2 isoforms [5]. The observed genomic organization of the bovine $E D 1$ gene was very similar to that of the human $E D 1$ gene and the mouse $t a$ gene. 


\subsection{Mutation analyses}

For mutation detection of the coding parts of the $E D 1$ gene, primer pairs flanking the exons were designed to amplify DNA samples from the available family members by PCR [5]. Subsequently each individual EDI exon could be screened for mutations by sequencing in comparison to a wild-type bovine control DNA. Additional RT-PCR experiments were performed to confirm detected genomic mutations at the EDI mRNA level. Amplified RT-PCR products were again directly sequenced.

In a family of black-and-white German Holstein cattle, PCR analyses of twelve available animals revealed that $E D 1$ exon 3 could not be amplified from affected animals indicating a genomic deletion of this exon (Fig. 1E). Unlike the situation in the first family, an EDI point mutation was observed in a second family of red-and-white German Holstein cattle. Sequencing of PCR products belonging to one affected male offspring (Fig. 1B: No. 2) and his dam (Fig. 1B: No. 1) revealed that the affected bull calf was hemizygous $G$ while the mother was heterozygous T/G at the second position of intron 8 (Fig. 1F) [7]. In both families all other EDI exons were unobtrusive and did not show any polymorphisms between the affected and unaffected animals [5,7].

The RT-PCR assay confirmed that the EDI mRNA from all affected animals of the black-and-white German Holstein family lacked exon 3 and revealed that three female individuals (Fig. 1A: No. 2, 7 and 10) were heterozygous carriers of the pathological X-linked inherited causative mutation [5,6]. RTPCR and cDNA sequencing demonstrated that a point mutation in the $5^{\prime}$ splice site following exon $8 \mathrm{~b}$ can affect the correct splicing of both the ED1-A1 and the ED1-A2 splice form. In an affected animal of the red-and-white German Holstein family the use of cryptic internal splice donor and acceptor sites within exon 8 (Fig. 1G) led to the production of a single transcript lacking 51 or 45 bp with respect to the physiological ED1-A1 or ED1-A2 transcripts, respectively [7]. In one human ED1 patient, a related mutation in the $5^{\prime}$ splice site following exon $8 \mathrm{~b}$ (IVS8 $+5 \mathrm{G}>\mathrm{A}$ ) of the $E D 1$ gene has been reported and it is speculated that this mutation might affect the ED1-A1 transcript only [25]. Since the analyses indicate the presence of an important splice enhancer at the beginning of intron 8 , it might be worthwhile to investigate the consequences on transcript processing in this human patient experimentally.

The deletion of EDI exon 3 (Fig. $1 \mathrm{H}$ ) produces a frameshift leading to a truncated protein that lacks the collagen-like trimerization domain as well as the functionally important TNF-like signaling domain of the ectodysplasin A1 and A2 proteins (Fig. 1I). On the protein level the consequence of the splice site mutation (Fig. $1 \mathrm{H}$ ) was predicted to result in an in-frame deletion of a large portion of the functionally important TNF-like signaling domain of ectodysplasin 1 (Fig. 1I). Reasoning from the genetic findings the X-linked inherited phenotype in the affected cattle with hypotrichosis, oligodontia, 
and absent eccrine glands is indeed caused by mutations of the ED1 gene and therefore accordingly termed as anhidrotic ectodermal dysplasia (ED1) in cattle.

\section{CONCLUDING REMARKS}

The cloning and sequence characterization of the bovine EDI gene as one of the largest known genes in cattle will extend our understanding of the bovine genome where still only very limited genomic DNA information is available. Furthermore, the reviewed EDI mutations causing X-linked anhidrotic ectodermal dysplasia in two independent cattle families represent an excellent example for the successful application of the comparative gene mapping approach. RT-PCR sequencing confirmed the genomic findings and represents a molecular genetic test system for the unequivocal classification of affected animals and the identification of heterozygous carriers. Both mutations cause rather large deletions within the ectodysplasin proteins and probably represent a complete loss of functional mutants. Therefore, the bovine ectodermal dysplasia phenotype described here represents a suitable animal model for the comparable ED1 phenotype in man and for the investigation of ectodysplasin 1 signaling pathways in development.

\section{ACKNOWLEDGEMENTS}

This study was supported by grants of the German Fonds of the Chemical Industry FCI and the German Research Council DFG (Le 1032/4-1+2) to T.L.

\section{REFERENCES}

[1] Bayés M., Hartung A.J., Ezer S., Pispa J., Thesleff I., Srivastava A.K., Kere J., The anhidrotic ectodermal dysplasia gene $(E D A)$ undergoes alternative splicing and encodes ectodysplasin-A with deletion mutations in collagenous repeats, Hum. Mol. Genet. 7 (1998) 1661-1669.

[2] Braun U., Ansari H.A., Hediger R., Süss U., Ehrensperger F., Hypotrichosis and oligodontia associated with a chromosomal Xq-deletion in a Simmental/Red Holstein crossbreed [German], Tierärztl. Prax. 16 (1988) 39-44.

[3] Chen Y., Molloy S.S., Thomas L., Gambee J., Bachinger H.P., Ferguson B., Zonana J., Thomas G., Morris N.P., Mutations within a furin consensus sequence block proteolytic release of ectodysplasin-A and cause X-linked hypohidrotic ectodermal dysplasia, Proc. Natl. Acad. Sci. USA 98 (2001) 7218-7223.

[4] Drieux H., Priouzeau M., Thiéry G., Priouzeau M.L., Hypotrichose congénitale avec anodontie, acérie et macroglossie chez le veau, Rec. Med. Vet. 126 (1950) 385-399. 
[5] Drögemüller C., Distl O., Leeb T., Partial deletion of the bovine ED1 gene causes anhidrotic ectodermal dysplasia in cattle, Genome Res. 11 (2001) 1699-1705.

[6] Drögemüller C., Kuiper H., Peters M., Guionaud S., Distl O., Leeb T., Congenital hypotrichosis with anodontia in cattle: A genetic, clinical and histological analysis, Vet. Dermatol. 13 (2002) 307-313.

[7] Drögemüller C., Peters M., Pohlenz J., Distl O., Leeb T., A single point mutation within the EDl gene disrupts correct splicing at two different splice sites and leads to anhidrotic ectodermal dysplasia in cattle, J. Mol. Med. 80 (2002) 319-323.

[8] Drögemüller C., Kuiper H., Leeb T., Peters M., Pohlenz J., Distl O., Congenital hypotrichosis and oligodontia in cattle [German], Tierärztl. Prax. 31 (2003) 70-76.

[9] Elomaa O., Pulkkinen K., Hannelius U., Mikkola M., Saarialho-Kere U., Kere J., Ectodysplasin is released by proteolytic shedding and binds to the EDAR protein, Hum. Mol. Genet. 10 (2001) 953-962.

[10] Ezer S., Bayés M., Elomaa O., Schlessinger D., Kere J., Ectodysplasin is a collagenous trimeric type II membrane protein with a tumor necrosis factor-like domain and co-localizes with cytoskeletal structures at lateral and apical surfaces of cells, Hum. Mol. Genet. 8 (1999) 2079-2086.

[11] Ferguson B.M., Brockdorff N., Formstone E., Ngyuen T., Kronmiller J.E., Zonana J., Cloning of Tabby, the murine homolog of the human EDA gene: evidence for a membrane-associated protein with a short collagenous domain, Hum. Mol. Genet. 6 (1997) 1589-1594.

[12] Headon D.J., Overbeek P.A., Involvement of a novel Tnf receptor homologue in hair follicle induction, Nat. Genet. 22 (1999) 370-374.

[13] Headon D.J., Emmal S.A., Ferguson B.M., Tucker A.S., Justice M.J., Sharpe P.T., Zonana J., Overbeek P.A., Gene defect in ectodermal dysplasia implicates a death domain adapter in development, Nature 414 (2001) 913-916.

[14] Kere J., Srivastava A.K., Montonen O., Zonana J., Thomas N., Ferguson B., Munoz F., Morgan D., Clarke A., Baybayan P., Chen E.Y., Ezer S., SaarialhoKere U., de la Chapelle A., Schlessinger D., X-linked anhidrotic (hypohidrotic) ectodermal dysplasia is caused by mutation in a novel transmembrane protein, Nat. Genet. 13 (1996) 409-416.

[15] Koppinen P., Pispa J., Laurikkala J., Thesleff I., Mikkola M.L., Signalling and subcellular localization of the TNF receptor Edar, Exp. Cell. Res. 269 (2001) 180-192.

[16] Kumar A., Eby M.T., Sinha S., Jasmin A., Chaudhary P.M., The ectodermal dysplasia receptor activates the nuclear factor-kappaB, JNK and cell death pathways and binds to ectodysplasin, J. Biol. Chem. 276 (2001) 2668-2677.

[17] Locksley R.M., Killeen N., Lenardo M.J., The TNF and TNF receptor superfamilies: integrating mammalian biology, Cell 104 (2001) 487-501.

[18] Mikkola M.L., Pispa J., Pekkanen M., Paulin L., Nieminen P., Kere J., Thesleff I., Ectodysplasin, a protein required for epithelial morphogenesis, is a novel TNF homologue and promotes cell-matrix adhesion, Mech. Dev. 88 (1999) 133-146.

[19] Monreal A.W., Zonana J., Ferguson B., Identification of a new splice form of the EDAl gene permits detection of nearly all X-linked hypohidrotic ectodermal dysplasia mutations, Am. J. Hum. Genet. 63 (1998) 380-389. 
[20] Monreal A.W., Ferguson B.M., Headon D.J., Street S.L., Overbeek P.A., Zonana J., Mutations in the human homologue of mouse dl cause autosomal recessive and dominant hypohidrotic ectodermal dysplasia, Nat. Genet. 22 (1999) 366-369.

[21] Nicholas F.W., Genetic databases: online catalogues of inherited disorders, Rev. Sci. Tech. 17 (1998) 346-350.

[22] Online Mendelian Inheritance in Man, OMIM (TM). McKusick-Nathans Institute for Genetic Medicine, Johns Hopkins University (Baltimore, MD) and National Center for Biotechnology Information, National Library of Medicine (Bethesda, MD) (2000) http://www.ncbi.nlm.nih.gov/omim/

[23] Rieck G.W., Hypotrichie-Hypodontie-Syndrom beim Rind [German], Dtsch. Tierärztl. Wschr. 92 (1985) 328-329.

[24] Schmidt-Ullrich R., Aebischer T., Hulsken J., Birchmeier W., Klemm U., Scheidereit C., Requirement of NF-kappaB/Rel for the development of hair follicles and other epidermal appendices, Development 128 (2001) 3843-3853.

[25] Schneider P., Street S.L., Gaide O., Hertig S., Tardivel A., Tschopp J., Runkel L., Alevizopoulos K., Ferguson B.M., Zonana J., Mutations leading to X-linked hypohidrotic ectodermal dysplasia affect three major functional domains in the tumor necrosis factor family member ectodysplasin-A, J. Biol. Chem. 276 (2001) 18819-18827.

[26] Selmanowitz V.J., Ectodermal dysplasias in cattle - Analogues in man, Br. J. Dermatol. 84 (1970) 258-265.

[27] Srivastava A.K., Pispa J., Hartung A.J., Du Y., Ezer S., Jenks T., Shimada T., Pekkanen M., Mikkola M.L., Ko M.S.H., Thesleff I., Kere J., Schlessinger D., The tabby phenotype is caused by mutation in a mouse homologue of the $E D A$ gene that reveals novel mouse and human exons and encodes a protein (ectodysplasin-A) with collagenous domains, Proc. Natl. Acad. Sci. USA 94 (1997) 13069-13074.

[28] Srivastava A.K., Durmowicz M.C., Hartung A.J., Hudson J., Ouzts L.V., Donovan D.M., Cui C.Y., Schlessinger D., Ectodysplasin-A1 is sufficient to rescue both hair growth and sweat glands in tabby mice, Hum. Mol. Genet. 10 (2001) 2973-2981.

[29] Wijeratne W.V.S., O’Toole D., Wood L., Harkness J.W., A genetic, pathological and virological study of congenital hypotrichosis and incisor anodontia in cattle, Vet. Rec. 122 (1988) 149-152.

[30] Yan M., Wang L.C., Hymowitz S.G., Schilbach S., Lee J., Goddard A., de Vos A.M., Gao W.Q., Dixit V.M., Two-amino acid molecular switch in an epithelial morphogen that regulates binding to two distinct receptors, Science 290 (2000) 523-527.

[31] Yan M., Zhang Z., Brady J.F., Schilbach S., Fairbrother W.J., Dixit V.M., Identification of a novel death domain-containing adaptor molecule for ectodysplasin-A receptor that is mutated in crinkled mice, Curr. Biol. 12 (2002) 409-413. 